\title{
Rights to Intellectual Works Generated with Artificial Intelligence: A Russian View in the Global Context
}

\section{$\Omega$ 同 Vitaly Kalyatin}

Associate Professor, Department of Theory of Law and Interdisciplinary Studies, National Research University Higher School of Economics, Doctor of Juridical Sciences. Address: 20 Myasnitskaya Str., Moscow 101000, Russia. E-mail: kalvit@yandex.ru

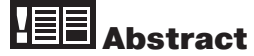

The broad use of artificial intelligence in creating intellectual works poses difficulties for legislators and courts in choosing the proper legal framework for such works and defining the place of artificial intelligence in the legal system as a whole. In this article, we shall study different models of regulating such issues and analyze the prospects and consequences of their use. We show that only a few of many different models for copyrighting Al-generated works are viable and that the most promising among them is the introduction of a special limited related right for the person who organizes the use of the Al application. This model resembles already existing civil law approaches to protecting the rights of phonogram producers, broadcasting and cablecasting organizations, and database creators. Thus, the inclusion of artificial intelligence into the IP domain does not require reconstructing the legal framework but only adapting existing approaches.

\section{O-1圆 Keywords}

intellectual property, artificial intelligence, authors' rights, related rights, author, creative activity, creativity, public domain, user, investor, organizer of Al use.

For citation: Kalyatin V.O. (2021) Rights to Intellectual Works Generated with Artificial Intelligence: A Russian View in the Global Context. Legal Issues in the Digital Age, no 1, pp. 42-63.

DOI: $10.17323 / 2713-2749.2021 .1 .42 .63$

\section{Introduction}

The protection of AI-generated intellectual works is a topical legal issue today: the growing possibilities of modern computers, on the one hand, and their broad involvement in the process of creating intellectual works, 
on the other, pose the question of choosing the right legal framework for works generated by artificial intelligence. The diversity of potential approaches to regulating relations in this domain requires the selection of basic models, which would then be developed to cover all possible cases. Such systematization would allow choosing fundamental approaches to solving the posed problem and adapting them to specific countries.

Nevertheless, the problem of determining the copyright owner of such works is much more important than solving the purely practical task of protecting the resulting rights. Already today, AI-generated outputs are often virtually indistinguishable from human-made works or even surpass the latter in popular opinion. ${ }^{1}$

Mankind must therefore take a stance (in particular, in the legal domain) on intellectual property not created by man, which is becoming increasingly common today. ${ }^{2}$ Moreover, the role of electronic technologies in human life will only grow with time, leading to an ever greater number of civil law issues involving AI. The resolution of this seemingly minor problem may have a major impact on the further development of civil law.

\section{Definition of artificial intelligence}

By its nature, artificial intelligence (AI) may be considered to be computer software, which is a well-developed notion in law. However, the most common approach to AI today is to view it as an instrument used in human activity and thus as an object of law. As a result, the question of rights to an AI-generated work is replaced to all intents and purposes by the question of whether a person made a creative contribution to its generation (the use of creativity in the generation of a work is considered a key aspect today for determining the work's protectability).

On the one hand, this allows the application of traditional approaches to regulating rights to such intellectual works in order to settle copyright issues with the help of law. On the other, it weakens the protection of

${ }^{1}$ During a study conducted by Rutgers University (USA) in 2017, a group of computer scientists and art historians were unable to tell paintings generated by artificial intelligence apart from paintings made by human beings. In a number of cases, paintings generated by AI were given higher assessment. Autonomous "creation": Authorship and protectability // Lauber-Rönsberg: Autonome "Schöpfung" - Urheberschaft und Schutzfähigkeit GRUR 2019, 244. Beck-online.

2 As, for example, in the controversial case of "monkey selfies" made with the camera of photographer D. Slater. Available at: https://en.wikipedia.org/wiki/Monkey_selfie_ copyright_dispute (accessed: 16.04.2020) 
works whose generation did not involve a creative contribution by a human being.

The situation is somewhat simpler in common law jurisdictions, where a softer criterion of creativity is used. Nevertheless, this does not eliminate the risks to human creativity that arise from the mass use of computer systems.

This scenario is a lot more difficult to implement in civil law jurisdictions, including Russia.

Thus, it is not sufficient simply to weaken the criteria for the protected object; one must also introduce regulations that take the specific nature of AI use into account.

Computer systems can be used to different extents to generate intellectual works: the degree of their participation can range from the simple fixation of an object (text, photograph, sounds) to the complex processing of material in which the role of the user of the computer system simply involves selecting the task or initial material.

Clearly, when the computer system is only used as an instrument for recording the user's activities, no major regulatory problems arise. The same holds when a user processes material (e.g., a photograph or text) with the help of a computer that acts as a technical device for changing or checking the material in accordance with the user's instructions.

The problem arises when the computer acts without any direct human participation in the process. Although a person may, in fact, play a role in the process by, say, formulating the principles of action or rules of behavior of the computer system, the latter acts as an autonomous system during the actual problem-solving process (even if a certain degree of user participation in the situation is required).

In view of the above, we may take as a basic definition the version proposed by the World Intellectual Property Organization: "Artificial intelligence (AI) is a discipline of computer science that is aimed at developing machines and systems that can carry out tasks considered to require human intelligence, with limited or no human intervention." In the narrow sense, this term refers to "techniques and applications programmed to perform individual tasks."

${ }^{3}$ WIPO conversation on intellectual property (IP) and artificial intelligence (AI), 2nd session. 2020. Available at: https://www.wipo.int/meetings/en/details.jsp?meeting_id=55309 (accessed: 25.11.2020) 
Although such a definition is fairly convenient for limiting the field of study, one must keep in mind that assessing the necessity for the participation of human intelligence in solving a problem remains extremely subjective.

When considering these issues, one must note that $\mathrm{AI}$ is no analogue of human intelligence either in its organization or in its operation. In this regard, it is useful to recall John Searle's thought experiment called "the Chinese room argument" [Searle J., 1990: 26-31]. It goes as follows: if a person shut up in a room is given instructions about how and when to use Chinese hieroglyphs to respond to a question in Chinese, he will be able to answer questions, and his responses may appear intentional and reasonable to a Chinese speaker outside the room. Nevertheless, the person shut in the room does not, in reality, understand the meaning of the questions or his answers.

This thought experiment shows the theoretical possibility of organizing information processing in such a way as to generate well-founded and seemingly reasonable answers through the mechanical use of preset rules of action and examples of analogous tasks ("weak AI"). The application of weak AI is naturally limited to the range of tasks for which it is programmed; in contrast, "strong AI" should be able to solve problems in virtually any field. However, no systems developed so far permit us to speak of the existence of strong AI.

At the same time, neural networks are capable of self-learning, which can be potentially used to create strong AI.

Law and legal doctrine also employ other definitions of AI. For example, GOST standard \#15971-90 (Table 1, item 56) defines AI as the "capacity of a computer to model the thought process by performing functions that are usually associated with human intelligence. Examples of such functions include learning and logical reasoning." In turn, item 5 of the Russian National Strategy for the Development of Artificial Intelligence up to the Year 2030 defines AI as "the set of technological solutions used for imitating the cognitive functions of man (including self-learning and searching for solutions without any preset algorithm) and for obtaining results in implementing specific tasks that are at least comparable with the results of human intellectual activity. This complex of technological solutions includes ICT infrastructure, software (including software employ-

${ }^{4}$ GOST 15971-90. State standard of the USSR. Information processing systems. Terms and definitions (approved and enacted by the Decree of the Committee for Standardization of the USSR no 2698). 
ing machine-learning methods), and processes and services for processing data and finding solutions." 5

While many other definitions of AI exist in different countries, they generally either draw analogies with human intellectual activity or list specific functions performed by artificial intelligence.

An example of the first type of definition is the Singapore National AI Strategy that characterizes AI as the capacity to model human intellectual activity with the help of a computer. ${ }^{6}$ In turn, the UAE National Program for Artificial Intelligence defines it as the set of technologies that allow a machine or system to understand, learn, act and feel as a human being. Such approaches are quite understandable: they make it possible to regulate this domain without getting bogged down in theoretical discussions. Nevertheless, they are not very productive, as there is an enormous difference between the organization of human intelligence and the operation of electronic devices. As a result, all attempts to compare them shall always remain tentative and superficial.

Definitions of the second type are currently being discussed in the EU and USA. For example, the European Resolution proposes the following criteria of "smart autonomous robots": (1) acquisition of autonomy through sensors and/or by exchanging data with the environment and trading and analyzing such data, (2) self-learning from experience and by interaction, (3) at least a minor physical support, (4) the adaptation of behavior and actions to the environment, and (5) the absence of life in the biological sense. ${ }^{7}$ The Future of Artificial Intelligence Act currently under discussion in the USA defines AI as any artificial systems that (1) perform tasks under varying and unpredictable circumstances, without significant human oversight, or learn from their experience and improve their performance, or (2) think like humans, or (3) act like humans (such as systems that can pass the Turing test or other comparable tests), or (4) seek to approximate some cognitive task, or (5) act rationally and achieve goals via

${ }^{5}$ Russian Presidential order no 490 "On the development of artificial intelligence in the Russian Federation" (together with the National AI Development Strategy until 2030) // SPS Consultant Plus.

${ }^{6}$ Available at: https://www.smartnation.gov.sg/docs/default-source/default-document-library/national-ai-strategy.pdf?sfvrsn=2c3bd8e9_\%D1\%81.\%204, 12 (accessed: 25.11.2020)

7 European Parliament resolution with recommendations to the Commission on Civil Law Rules on Robotics (2015/2103(INL). 2017, February 16. Available at: http://www.europarl.europa.eu/sides/getDoc.do?type $=$ TA\&reference $=$ P8-TA-2017-0051\&language $=E N$ (accessed: 16.04.2020) 
perception, planning, reasoning, learning, communicating, decision making, and acting. ${ }^{8}$

Similar criteria have been proposed by Russian specialists. For example, V. Naumov and E. Tytyuk have formulated the following characteristics of an AI application: (1) created for processing information, (2) able to analyze information about the environment, (3) autonomous implementation of algorithms, and (4) capacity for self-learning during implementation without human interference [Naumov V.B., Tytyuk E.V., 2018: 533].

All the aforementioned criteria mostly pertain to the decision-making process of AI rather than its intrinsic nature. At the same time, the conformity of a computer system to these criteria says nothing about the quality of the results. Clearly, when assessing the protectability of an intellectual work, the user cannot take the organization of the computer system into account. For the purposes of protecting IP, one should therefore treat AI as a "black box" and only assess the intellectual work itself.

To this end, it is important to define the criteria that such an intellectual work must conform to.

\section{General approaches to copyrighting Al-generated intellectual works}

In its Plenary Decision no 10 "On applying $\$ 4$ of the Civil Code of the Russian Federation" of April 23, 2019, the Russian Supreme Court wrote, "When examining cases of attributing authors' rights to a specific intellectual work, courts should keep in mind that, by the import of $\$ \$ 1228$, 1257 and 1259 of the Civil Code of the Russian Federation taken together, only intellectual works resulting from creative activity are subject to such rights. One should also keep in mind that, until established otherwise, an intellectual work must be the result of creative activities. It should be also kept in mind that the lack of novelty, uniqueness and/or originality per se in an intellectual work does not necessarily indicate that such a work is not the result of creative activity and thus is not subject to authors' rights. The creative nature of a work does not depend on whether the work was made by an author on his own or with the help of technical means. At the same time, works made with technical means without any human creative activity (for example, photos and videos made by an automatic video camera used for recording civil infractions) are not subject to authors' rights" (item 80).

${ }^{8}$ H.R. 4625. Future of artificial intelligence act of 2017, 115th Congress (2017-2018). Available at: https://www.congress.gov/bill/115th-congress/house-bill/4625/text (accessed: 19.06.2019) 
Thus, with regard to the protectability of intellectual works, current Russian judicial practice makes a distinction between a work made by a human being and a work made by a machine without human participation. Such an approach is used in other countries, too. For example, the US Copyright Office registers intellectual works only if they are created by human beings, ${ }^{9}$ while courts systematically reject all attempts to attribute copyrights to works not made by humans (e.g., works made by an animal ${ }^{10}$ or by the holy spirit $\left.{ }^{11}\right)$. Some countries qualify this by insisting on the creative nature of the activity used to make the work, ${ }^{12}$ while others explicitly specify that an author can only be a human being. ${ }^{13}$

The stress on the creative nature of a work makes it impossible (within the framework of the current Russian model) to protect AI-generated works. This may require changing the current criteria of the protectability of such works. Such an approach is based on the importance attached to creativity today.

Thus, if we want to extend authors' rights to AI-generated works, we must either change our approach to the criterion of creativity (for example, by interpreting this criterion more broadly so as to extend it to AI-generated works or take different approaches to copyrighting human-made and AI-generated works.

We should note in this regard that the selection of criteria for the protectability of works cannot be considered separately from the designation of the person in whom the author's right is vested. Irrespective of the approach, the choice of criteria and the rights holder is determined by the social goals of copyrighting.

These goals lie in several different planes.

The main goal of copyrighting IP is to stimulate socially significant work for creating such property. This is shown by the choice of both the rights holder and the conditions of protecting the property. The introduction of copyrighting has encouraged authors to create new works, as the

${ }^{9}$ Compendium of U.S. Copyright Office practices. Para 306. 2017. Available at: https:// www.copyright.gov/comp3/chap300/ch300-copyrightable-authorship.pdf (accessed: 20.06.2019)

10 Naruto v. Slater, \#16-15469 (9th Cir. 2018).

11 U.S. Court of Appeal Ninth Circuit June 10, 1997, Urantia Foundation v. Maaherra, 114 F.3d 955, 963-964.

12 For example, $\$ 2$ of the Copyright law of Japan stipulates that only works that creatively express thoughts or emotions are copyrightable.

${ }^{13}$ Cf., for example, $\$ 7$ of the German act on copyright and related rights. 
main incentive of human behavior, at least in today's paradigm, is to improve one's material status [Karapetov A. G., 2016: 46]. In this regard, the stress on creativity leads to an increase in the stimulating effect thanks to moral factors (recognition of a person as an author). Indeed, moral incentives are often the most significant for authors, as they lead to the societal recognition of a person's uniqueness, special traits (talent), etc.

Nevertheless, it is important to keep in mind that copyrighting aims not only to recompense authors out of gratitude or fairness but also (and more importantly) to stimulate socially significant activities on their part.

At the same time, copyrighting IP stimulates not only the creation but also the disclosure of such works. To allow a person to derive profit from reproducible IP, a monopoly must be awarded to him. If the legislator does not create a legal monopoly (exclusive right), the author is obliged to maintain a factual monopoly - in particular, by keeping his intellectual work a secret. Nevertheless, such a state of things does not correspond to the goals of IP law [Sesitsky E. P., 2018: 133].

From the economic standpoint, assigning a right to a specific person is necessary to assure economic turnover, as the very development of a right is possible only on the condition of the clear-cut identification of the original rights holder. As Professor Dozortsev once said, "The creative result of intellectual activity bears the imprint of the author's personality. Thus, the original proprietary right of use, based on creative activity, is tied to the person of the author. And it is less a matter of protecting the interests of a person as such than of assuring normal economic turnover. Thus, authorship is important first and foremost as grounds for the emergence property rights and as the original point of reference for these rights: it is the result of the individualization of the original rights holder" [Dozortsev V.A., 2003: 145].

This goal is even more important in common law jurisdictions: "By recognizing and exploiting the fact that the law supported the view that an author was creating a piece of property which could be assigned a financial value, it became possible to move away from private to commercial patronage" [Feather J., 2010: 364]. This stimulates the consumption and commercial use of intellectual works and thus their creation.

Regardless of the jurisdiction to which a country belongs, both goals play an important role, even if legislators have different priorities. As one paper states, "...it is true to say that in the development of modern copyright laws, the economic and social arguments are given more weight in the Anglo-American laws, whereas, in Continental law countries, the natural law argument and the protection of the author are given first place" [Garnett K., James J., Davies G., 1999: 29]. 
Another goal is to allocate responsibilities during the circulation of rights. Nevertheless, this consideration does not play a major role, even if it should be kept in mind, as we will see when we discuss the model of attributing rights for a generated work to AI itself.

Finally, regulations in this domain can also try to lower the concomitant risks. Although AI is very important in contemporary society, its use also harbors certain dangers. AI is potentially capable of producing major problems for individuals engaged in intellectual activities, as human authors shall never be able to compete with $\mathrm{AI}$ in the speed and cost of creating new intellectual works in areas of mass production (especially in domains without high standards for the artistic value of the created works). If AI-generated works are not protected, they will be used to an ever greater extent by society to the detriment of human authors.

The aforementioned danger can be lowered by the timely introduction of a system for protecting AI-generated intellectual works involving greater limitations than usual authors' rights for similar intellectual works - in particular, in the duration and, possibly, extent of rights and cases of free usage. Although such a danger is still hypothetical today, its most effective solution involving the introduction of a limited right is possible when no commonly accepted approach has yet emerged in legislation or court practice (such as the recognition of full-fledged authors' rights for such objects).

In the final account, it is the legislators' goals that determine the choice of works whose creation shall be stimulated through the selection of rights holders and copyright criteria.

Numerous criteria of protectability are used in the world for works of authorship: novelty, uniqueness, originality, individuality, etc. Despite their diversity, they generally aim to stimulate the creation of intellectual works, on the one hand, and to limit the range of these works, on the other. For this reason, it would be insufficient to consider the "novelty" of works. Whereas it is possible to verify the novelty of a created work in the case of patent law, this is much more difficult to do in practice for works of authorship.

An even more important consideration is that the benefits from the introduction of an exclusive right (of a monopolistic nature) outweighs the negative consequences for society only in the case of socially significant intellectual works that cannot be created by everyone.

Thus, the criterion of creativity is aimed at defining the qualitative characteristics of a work that make it stand out among all works made by hu- 
man beings. Today, we can assess the nature of human intellectual activity only through its results. Thus, when we speak about the creativity of the author, we actually mean its reflection in the finished work, which serves as a reflection of human activity.

Nevertheless, it is not easy to make such assessments of a created work. As a result, courts tend to take other criteria into account, too. In particular, the Russian Supreme Court noted in 2006 that works of authorship include works that can be used independently and that are creative and original; ${ }^{14}$ the Court for Intellectual Property Rights used the criterion of uniqueness $;{ }^{15}$ one court of arbitration employed the criteria of originality and novelty; ${ }^{16}$ and so on.

In actual fact, the aforementioned criteria have no independent significance; rather, they are special cases of the criterion of creativity. For this reason, they can be used to facilitate the assessment of a work yet not to replace the criterion of creativity. This is why the Russian Supreme Court in its plenary decision cited above ruled that the lack of novelty, uniqueness and/or originality of a work of authorship does not in itself show that the work is not creative and thus that it is not copyrightable.

The criterion of creativity is used in continental law jurisdictions as well as in some common law countries (USA, Singapore). However, orientation on human inner psychological processes makes it difficult to use this criterion for assessing AI-generated intellectual works. Even if the rights holder is taken to be a person (programmer, user, etc.), the problem will still remain: it will not be easy to show that the work is creative or even that making such a work necessarily requires creativity.

Still, it is extremely important to continue to make qualitative assessments of intellectual works, as the use of electronic systems can lead to a multifold increase in the number of intellectual works without any utility for society.

At the same time, one can attain the same goals without the complicated process of assessing the intellectual activity of a work's creator. An example is the use of "qualitative" criteria in patent law: the criterion of inventiveness and analogous criteria such as the "inventive step," significant novelty, etc.

${ }^{14}$ Section 21 of the Plenary decision of the Supreme Court of the Russian Federation no 15 "On handling civil cases relating to the application of law on authors' and related rights.” 2006, June 19. (Expired) // SPS Consultant Plus.

15 Decision of the Court for Intellectual Property Rights on case no A12-18806/2013.

${ }^{16}$ Decision of the Court of Arbitration of the Sverdlovsk Oblast no A60-49303/2015. 
We thus see that, in the different models for copyrighting AI-generated intellectual works, the criteria for the protectability of such works should take the differences between AI operation and human intellectual activity into account.

\section{Models of protecting Al-generated intellectual works}

Theoretically, the following persons participating in the creation of intellectual works could be vested with copyrights in these works:

the person who develops the program on which the AI application is based;

the person who organizes the operation of the AI application that generates the intellectual work (for example, the investor in the project);

the user of the AI application;

the AI application itself;

Intermediate models are also possible: co-authorship between AI and a human being and fictional authorship.

One should also consider the possibilities of putting AI-generated works subject in the public domain and of excluding such works from copyright altogether.

None of these approaches has received unanimous support so far. Moreover, as one specialist has noted, all these concepts "have both advantages and disadvantages. None of them is fully adequate or fully wrong, and the full-fledged implementation of any of them will require a minor or major reform of existing law, including IP law" [Morkhat P., 2019: 240-241].

\section{A) The person who develops the Al application}

This approach may seem fairly straightforward, as it calls for applying already existing copyright criteria to intellectual works. In this case, AI is simply treated as an instrument that the author uses to create new intellectual works - a model that is well known in law.

Such an approach is set forth, for example, in a bill for amending $\$ 1228$ of the Russian Civil Code that was introduced to the State Duma by deputy A. Kobilev. ${ }^{17}$

17 Shestoperov D. Chto napisano softom. Plody iskusstvennogo intellekta zapishut za razrabotchikami [What is written by software: Rights to results of artificial intelligence 
At the same time, it is important to note that the author of the AI application largely predetermines its operation yet makes no contribution to the resulting work. For this reason, he cannot be viewed as the author of the works generated by the AI application, which would lead to a totally new approach in which the author's rights would extend to a group of intellectual works that the author did not create, as he only prepared the instrument for the user.

Such a situation would mean stimulating the creation of AI applications rather than the creation of intellectual works, i.e., the author would be stimulated to create new versions of AI applications (that may subsequently create an even greater number of new intellectual works) yet not to create new works of higher quality, as he does not participate in the process of applying these AI applications.

This would have a negative impact on society in general and on persons using AI in particular, as the latter would not receive any rights to the works created by their companies. In reality, software buyers usually expect to hold rights in the products they create with this software, and the existing concept of authors' rights agrees with this view.

At the same time, the approach discussed here would inevitably lead to market monopolies, as the rights to an enormous number of generated works shall be accorded to a few leading AI developers rather than to the multitude of competing persons using $\mathrm{AI}$ in their work.

Moreover, AI developers already receive sufficient compensation from selling rights to their products.

\section{B) The person who organizes the operation of the Al application and its generation of intellectual works}

A different situation arises when one focuses on the person who organizes the AI application's generation of intellectual works. Such a person may have access to the corresponding software in different ways: as the owner of an exclusive right or as a license holder or simply as the owner of the hardware on which the software is installed - this makes little difference.

Grounds for granting rights to such a person may include the recognition of the public utility of his activities and the need to encourage them. In particu-

shall be accorded to developers]. Available at: https://www.kommersant.ru/doc/456614 4?query=\%D0\%9A\%D0\%BE\%D0\%B1\%D0\%B8\%D0\%BB\%D0\%B5\%D0\%B2 (accessed: 10.11.2020) 
lar, during the discussion of AIPPI results, French jurists voiced the opinion that, with regard to copyrighting AI-generated works, the rights to the works should be granted to persons that initiated the creation of the works, managed the projects, and disclosed the works (by analogy with collective works mentioned in $\S$ L.113-5 of the French Intellectual Property Code). ${ }^{18}$

A similar theory was advanced by the German scholar Kummer, who argued that a person should be entitled to rights to a work for simply finding and disclosing it ("presentation theory") [Kreutzer T., 72, 73].

Nevertheless, the attempt to recognize such a person as the author does not fully correspond to the principle of authors' rights, and it is not surprising that this theory is fairly actively criticized in Germany today. It would be a lot more logical to speak not of an author's right but of a narrower related right and of a right granted to the organizer of the process of the work's creation, similar to the rights of phonogram producers, broadcasting and cablecasting organizations, etc. Related rights are the area where most German specialists try to place the rights to the objects discussed here [Selvadurai N., Matulionyte R., 2020: 536]. ${ }^{19}$

The advantage of this model is the fact that it stimulates the process of the creation of new intellectual works and gives the owner of an AI application the possibility of commercially exploiting it. At the same time, this model may attribute rights to the created works directly to the organizer of the process rather than to the natural person who uses the AI. This would deprive the natural person of any incentives to engage in creative activities. However, in view of the growing possibilities of AI, the user only performs technical functions in most cases, and his activities are rarely creative. This situation is basically similar to cases in which the law gives direct rights to organizers of certain activities such as making databases or phonographs and not to the operators that input the data into the system.

This model is already being implemented in some countries, including the United Kingdom (where it is set down by law) and the USA (court practice). It is also recognized by some other countries such as New Zealand [Selvadurai N., Matulionyte R., 2020: 543].

In Great Britain, the Copyright, Designs and Patents Act stipulates that computer-generated works can be copyrighted even in the absence of a hu-

${ }^{18}$ Study question AIPPI 2019: Copyright in artificially generated works. Para 7. Available at: https://aippi.soutron.net/Portal/DownloadImageFile.ashx?objectId=5292 (accessed: 15.01 .2020$)$

${ }^{19}$ Ibid. Para 13, 18. 
man author: ${ }^{20}$ a work is considered to be made by the person who makes the necessary preparations for its creation. ${ }^{21}$

There exist different interpretations of this law. For example, D. Vaver asserts that it creates the figure of a "fictional author" on grounds that have nothing to do with stimulating human creativity but only with protecting the object of investments from unscrupulous practice and misappropriation [Vaver, D., 1994: 162]. Other specialists say that the law is sufficiently broad to cover both the person who operates the computer and the person who provides or programs the computer [Bently L., Sherman B., 2004: 117]. Nevertheless, it should be said that it does not cover persons who perform purely technical functions (e.g., users inputting data into the device's memory) and thus once again privileges the organizer of the process.

Without a doubt, the role of the organizer of the process of generating an intellectual work is becoming increasingly decisive and, from the standpoint of public progress, merits to be rewarded. However, this model can be fully implemented only if special regulations are added to the law - for example, in the category of related rights. This will also make it possible, through the introduction of different frameworks, to demarcate human activity from AI operation and thus to minimize the risk of "deflating" the value of intellectual works as a result of the mass production of AI-generated works.

Yet would it not be better to stress investments rather than organizational activities and vest rights in persons investing in the development of an intellectual work? Such a model is implemented in the case of, say, database creators. Consequentially, it has been proposed to give priority to the investor in the case of intellectual works, too. ${ }^{22}$

Nevertheless, it should be said that the law connects the notion of the database creator first and foremost with organizational efforts (for example, $\$ 1333$, item 1, of the Russian Civil Code stipulates that "The database creator is a person who organizes the creation of the database and the work of collecting, processing and inputting its materials"), whereas the criterion of investments applies to the database itself rather than to the activities of the database creator. In other words, the law focuses on the organizational activity of a person and protects the database creator rather than the investor (e.g., the person who provides funds for the project). This is expressed in a less explicit manner in Directive 96/9/EC of the European

\footnotetext{
20 Ibid. Para 9(3), 178.

21 Ibid.

22 Study question AIPPI 2019... Para 13, 18.
} 
Parliament and Council of March 11, 1996, on the legal protection of databases; according to $\$ 7$, item 1 , it is the "database creator" who is protected.

Thus, one should make the notion of the "investor" include organizational functions. This is entirely justified, as organization plays a decisive role in the process of the creation of an intellectual work.

Another question is whether it makes sense to cite the amount of investments in an AI-generated work as an additional criterion of protectability. It seems to us that, with the exception of databases, it would be inexpedient to limit additionally the protection of works of authorship into which major investments have not been made, as AI can be used in highly diverse spheres, some of which do not require any special investments.

\section{C) The user of the Al application}

The AI user is a person who directly launches the implementation of the task and determines its parameters. This clearly allows him to pretend to certain rights with respect to the created work.

Moreover, in jurisdictions that do not require any major creative contributions to be made to the work (for example, in the United Kingdom by virtue of the "sweat of the brow" doctrine), any actions on choosing and improving AI-generated works may be considered creative [Samuelson P., 1986: 1185, 1204]. US court practice has precedents of the recognition of "quasi-property rights" (quasi-property treatment) even in the absence of any creative contribution to the work - as in the case of "breaking news" [Yu R., 2017: 1266-1268].

Proposals to give rights to AI users have also been made by Russian specialists [Nazarov N., 2020: 61].

Nevertheless, it must be kept in mind that the role of the AI user can range from exerting a major impact on the generated intellectual work to performing purely mechanical functions by inputting the required parameters into the system. While the activities of the user may be outwardly described in the same terms (such as launching a certain process), the key aspect is the user's awareness of the expected results: only if he has an idea of the characteristics of the future work can his activities be called "creative".

If the AI user's activities have a creative component, he shall be recognized as an author by existing law, too.

Thus, the problem arises when the AI user performs purely technical work. Vesting such a person with rights to created works would not en- 
courage him in any way: by the nature of his activities, he only carries out his superior's instructions.

Without a doubt, such rights would stimulate the AI user's employer. The employer would obtain rights from his employees, as the works are created in the framework of employment relations, while getting rights to the works would encourage him to use AI more and to make products of higher quality. Nevertheless, as the original rights are granted to the employees in a random manner due to the technical nature of their activities, the introduction of this added complication seems totally unwarranted. In this regard, the present approach has no advantages over the model described in the previous section.

At the same time, this approach can have a negative impact on the user's activities by stimulating him to search for effective software that would do everything for him instead of trying to create new intellectual works himself [Perri M., Margoni T., 2010: 626]. This is hardly in the interests of society.

\section{D) The Al application}

On the whole, legal doctrine has taken a fairly negative view of the idea of vesting rights to intellectual works in the AI application itself.

The crux of the matter does not really lie in the fact that, as some specialists note, computers are unable to protect their own rights or sign contracts on transferring rights to others [Solum L., 1992]. One should note that the absence of human beings is no obstacle to granting rights to a legal entity - an example is the institute of legal persons. Nevertheless, this requires the recognition of the legal capacity and competence of such a person, which needs careful justification. In legal history, the introduction of such entities always results from the necessity to limit the liability of commercial activities, which could also serve as grounds in the present case, as the activities of AI can damage other persons. Indeed, A. Morrigi asserts that the main obstacle to granting rights to $\mathrm{AI}$ is the impossibility of making it liable for its actions.

At the same time, the recognition of an entity as being liable requires it to possess certain property - otherwise, it shall be simply used by the owners of an AI application to evade liability. Thus, an AI application would have to be considered liable for its activities and capable of conducting these activities in its own name and making profits from these activities.

Nevertheless, it remains unclear whether the introduction of such a legal entity as AI would give any advantages over the existing institute of the 
legal person. Most likely, it would only complicate matters further without producing any positive effects at the present time.

Clearly, AI requires no incentives today, and thus granting it rights would not encourage the development and introduction of new intellectual works.

This explains why this model is not considered seriously by specialists today. However, the situation may change in the future.

\section{E) Co-authorship between $\mathrm{Al}$ and human beings}

Another way of stimulating a wide group of persons participating in the creation of intellectual works would be to use the institute of co-authorship: for example, viewing the programmer and user as co-authors. Some people have proposed considering the developer of a software program that is capable of self-learning and the user of such a program as co-authors even in the absence of direct cooperation during the creation of the work. ${ }^{23}$

Nevertheless, the advantages of this model are deceptive, as it brings together the shortcomings of the aforementioned models: it stimulates users to borrow others' products, often without making any significant contributions to them [Kumar S., Lavery N.], as well as encouraging the appearance of monopolies of AI developers (by extending their rights to AI-generated products). One should also note that such an approach does not conform to the practice of regulating co-authorship in copyright law, which states that only persons jointly engaged in a creative activity may be called co-authors.

Another model envisages co-authorship between the user (who engages in creative activity, for example) and the AI application. In 1986, the US Congress Office of Technology Assessment criticized an earlier view of computers as passive instruments, noting that the growing complexity of computer programs and the interactive nature of calculations makes it increasingly probable that computers will be recognized as co-authors of human beings in the future. ${ }^{24}$

Nevertheless, such an approach does not provide any evident advantages. Given that the activities of human beings and artificial intelligence

${ }^{23}$ Levy v. Rutley (1871). Available at: https://swarb.co.uk/levy-v-rutley-ccp-1871/ (accessed: 21.12.2019); Hodgens v. Beckingham (2003). Available at: https://www.casemine. com/judgement/uk/5a8ff7a460d03e7f57eb0ad1 (accessed: 10.06.2017)

${ }^{24}$ US Congress, Office of Technology Assessment (1986). Intellectual property rights in an age of electronics and information, 72 . 
cannot be evaluated on the basis of the same criteria (among other reasons, on account of their totally different organization), relating human and AI rights can make legal approaches a lot more complicated, while AI itself has no need of incentives (at least today).

\section{F) Fictional authorship}

Given that most countries copyright only works with authors, one way to solve the problem within the framework of the existing legislation would be to choose a provisional author. For example, in British law the organizer of the creation of a work is factually recognized as the author; a similar approach exists in New Zealand; etc.

Another version of this model is a conception developed by T. Butler [Butler T., 1982: 744-745] that calls courts to select the person who made the greatest contribution to the creation of a work as its fictional author.

It should be said, however, that this model does not define conceptually who should be designated as the fictional author and therefore only offers the advantage of preserving the familiar approach that assumes that every intellectual work has an author. It may therefore be easier to introduce an independent protection mechanism within the framework of related rights without any reference to author status.

\section{G) Public domain/exclusion from copyright}

Grounds for not copyrighting AI-generated intellectual works include the lack of creativity (in the current sense) of artificial intelligence. As a result, Russia and many other countries only copyright intellectual works made by human beings, as we noted above. As artificial intelligence does not require any incentives to operate, it is commonly held that one can immediately permit the free use of AI-generated works.

Another version of this approach is to put AI-generated works into the public domain. For example, the United States Copyright Office had stated that works of authorship not created by human beings are in the public domain, i.e., not copyrightable. ${ }^{25}$

It should be said that a work in the public domain is not fully excluded from legal regulation. On the contrary, public domain requires the respect

${ }^{25}$ Compendium of U.S. Copyright Office practice. Para 313.2. Available at: https:// copyright.gov/comp3/chap300/ch300-copyrightable-authorship.pdf, $\$ 313.2$ (accessed: 16.10.2020) 
of certain rules by persons using the work (for example, indicating the author's name, not making changes to the work, etc.). While the public domain is usually employed for intellectual works whose exclusive rights have expired, there is nothing that prevents it from being used for works that have never been copyrighted at all (see $\$ 1337$, item 1, of the Russian Civil Code, $\$ 313.6(\mathrm{D})$ of the Compendium of the United States Copyright Office ${ }^{26}$.

The reason to put an intellectual work in the public domain rather than leaving it totally unprotected is to preserve limited public control over its use. However, in the case of AI-generated works, one must define the conditions of their use in law: after all, it is necessary to protect the interests of persons involved in the creation of these objects and the authors of works used in the process.

Still, the main problem of this model is the fact that it eliminates incentives for the development of new intellectual works by AI users. On the one hand, it prevents the AI application's owner from drawing full economic advantages from the created works; on the other, it incites him to conceal his use of AI and attribute the work to a fictional author instead. A recent survey of AI experts showed that over $65 \%$ of them believe that computer programs, including AI programs, make the main contribution to creating contemporary works (music, movies, software, etc.).

It is very important to note that the broad application of artificial intelligence runs the risk of excluding human beings from creative activities and establishing new (and real) monopolies on the IP market by AI developers and users. The transfer of AI-generated works into the public domain would only aggravate this problem rather than solving it, as operators of artificial intelligence would begin to conceal its use in their works, attributing them to natural persons who only make a formal contribution to their creation.

One should also take into account the economic implications of public domain. In this regard, it is interesting to consider a model developed by Prof. Arti Kaur Rai of the University of San Diego School of Law. He identifies four categories of societal costs related to the creation and development of IP: (1) labor and capital expenditures on the development of the work, excluding expenditures on transferring rights ("pure development costs"), (2) expenditures on transferring rights ("transaction costs"), (3) costs resulting from lowered incentives for engaging in the corresponding creative

${ }^{26}$ Available at: https://www.copyright.gov/comp3/chap300/ch300-copyrightable-authorship.pdf (accessed: 11.04.2020) 
activities resulting from the control of basic research by one copyright holder ("creativity costs"), and (4) expenditures on formulating research that leads to the creation of the work ("invention costs").. Depending on the relation of these four types of costs, one can determine the expediency of putting a given work in the public domain. For example, Rai supports the approach taken by some US universities to encourage the privatization of an intellectual work if the transaction and creativity costs are low and discourage its privatization if these costs are high [Rai A., 1999: 136, 145]. Here, the "pure development costs" and "invention costs" should be measured as the amounts needed to reimburse the corresponding expenditures.

For example, a university that makes a revolutionary discovery in medicine has, as a rule, high invention and transaction costs (to compensate for expenditures on the development of the discovery) as well as high creativity costs (the patent can prevent the development of a whole field of science). For this reason, it would be quite expedient for society to put such a discovery in the public domain.

Let us try to apply this approach to AI-generated intellectual works. The pure development costs are average during the first stage of AI application and fall rapidly thereafter, because artificial intelligence is able to produce a large number of results over a short period of time. The transaction costs are small: a single work can be licensed to a series of users with fairly low expenditures. While the creativity costs depend on the type of the work, they are usually quite low in the domain of authors' rights due to the lack of hindrances to the creation of analogous works by other persons. The invention costs are also quite small.

Clearly, in the framework of this model, putting AI-generated intellectual works in the public domain would not lower societal costs but only discourage persons from applying artificial intelligence.

\section{Conclusion}

Our analysis of existing models has shown that, their diversity notwithstanding, only a few of these models stimulate the creation and use of new intellectual works. The most promising model seems to be vesting the rights to an AI-generated work in the organizer of the process of its creation.

Rights to AI-generated works should be more limited than traditional exclusive authors' rights so as to protect the interests of human authors.

In this case, any person who is professionally involved in the creation of IP shall have a choice: using AI to create an intellectual work at a lower 
cost while getting a fairly limited right for a relatively short period of time or paying more for the creation of an intellectual work by a human author while getting rights for a longer period. One can surmise that, over time, consumers will increasingly value intellectual works made by human beings (similarly to the value assigned today to unique and hand-made goods).

For this reason, one should make it obligatory for producers to designate whether AI was used to make an intellectual work. This will allow consumers to choose between books and films made by human beings and machines.

In conclusion, we should note that it is pointless to vest AI applications with rights today. At the same time, it appears highly promising to attribute rights to the organizer of the use of AI for the creation of intellectual works. Nevertheless, such a model is not totally new to IP law (it suffices to recall the rights of phonogram producers, broadcasting and cablecasting organizations, and database creators). Thus, the inclusion of artificial intelligence into the IP domain does not require reconstructing the legal framework but only adapting existing approaches.

\section{I国 References}

Bently L., Sherman B. (2004) Intellectual property law. Oxford: University, $1131 \mathrm{p}$.

Butler T. (1982) Can a computer be an author: Copyright aspects of artificial intelligence. Hastings Comm \& Ent., no 4, pp. 707-747.

Dozortsev V.A. (2003) The right to a film as a complex multilevel work. In: Intellectual Rights: Terms. System. Aim of Codification. Moscow: Statut, pp. $143-170$.

Feather J. (2010) The significance of copyright history. In: Privilege and property: Essays on the history of copyright. N.Y.: Open Books, pp. 359368.

Garnett K., James J., Davies G. (1999) Copinger and Skone James on copyright. L.: Sweet \& Maxwell, 1225 p.

Hristov K. (2020) Artificial intelligence and the copyright survey. Available at: https://ssrn.com/abstract=3490458 or: http://dx.doi.org/10.2139/ ssrn.3490458 (accessed: 1.02.2021)

Jaszi P. (1992) On the author effect: Contemporary copyright and collective creativity. Cardozo Arts and Entertainment Law Journal, no 2, pp.293-320.

Kalyatin V.O. (2016) Defining public domain in contemporary information society. Pravo. Zhurnal Vysshey shkoly economiki, no 2, pp. 4-14 (in Russian) 
Karapetov A.G. (2016) Economic analysis of law. Moscow: Statut, 528 p. (in Russian)

Kreutzer T. (2008) The model of German copyright law and regulation alternatives. Available at: https://www.nomos-elibrary.de/10.5771/ 9783845212197.pdf?download_full_pdf=1 (accessed: 2.02 .2021 )

Kumar S., Lavery N. (2019) Does Al generated work give rise to a copyright claim? Available at: https://www.natlawreview.com/§/doesai-generated-work-give-rise-to-copyright-claim (accessed: 1.02.2021)

Morrigi A. (2017) The role of intellectual property in the intelligence explosion. Available at: https://www.4ipcouncil.com/application/ files/9615/1638/1031/The_Role_of_Intellectual_Property_in_the_ Intelligence_Explosion.pdf. (accessed: 1.02.2021)

Nazarov N. (2020) Attribution of authorship to intellectual works generated by artificial intelligence. Intellektual'naya sobstvennost'. Avtorskoe pravo i smezhnye prava, no 3, pp. 53-62 (in Russian)

Naumov V.B., Tytyuk E.V. (2018) Legal status of the "creative" work of artificial intelligence. Pravovedenie, no 3, pp. 531-540 (in Russian)

Perri M., Margoni T. (2010) From music tracks to Google maps: Who owns computer-generated works? Computer Law and Security Review, no 6, pp. 621-629.

Prange D., Lawson A. (2018) Re-evaluating companies' Al protection strategies. Managing Intellectual Property, no 272, pp. 35-38.

Rai A. (1999) Regulating scientific research: Intellectual property rights and the norms of science. Northwestern University Law Review, no 1, pp. 77-152.

Samuelson P. (1986) Allocating ownership rights in computer-generated works. University of Pittsburgh Law Review, vol. 47, pp.1185-1204.

Searle J. (1980) Minds, brains, and programs. Behavioral and Brain Sciences, no 3, pp. 417-424.

Selvadurai N., Matulionyte R. (2020) Reconsidering creativity: Copyright protection for works generated using artificial intelligence. Journal of Intellectual Property Law \& Practice, no 7, pp. 536-543.

Solum L. (1992) Legal personhood for artificial intelligences. Available at: https://scholarship.law.unc.edu/cgi/viewcontent. cgi?§=3447\&context=nclr (accessed:1.02.2021)

Vaver D. (1994) Translation and copyright: A Canadian focus. European Intellectual Property Review, no 4, pp.159-166.

Yu R. (2017) The machine author: what level of copyright protection is appropriate for fully independent computer-generated works? University of Pennsylvania Law Review, no 165, pp. 1266-1268. 